Michael Haugh* and Yasuko Obana

\title{
Transformative continuations, (dis)affiliation, and accountability in Japanese interaction
}

DOI 10.1515/text-2015-0015

\begin{abstract}
Studies of joint productions have often focused on instances where a recipient anticipates through completions what a speaker might be about to say, or through expansion what that speaker could plausibly go on to say. However, recent work suggests that grammatically fitted continuations may also alter or redirect the projected trajectory of a prior speaker's turn or utterance. In this paper, building on this prior work, we focus on cases in Japanese interaction where grammatically fitted continuations of one speaker's turn or utterance by another speaker accomplished through "format tying" (Goodwin and Goodwin 1987) effects some kind of transformation of the action or stance implemented by that prior turn. We term these "transformative continuations," and propose that while they are invariably disaligning, they may nevertheless implement both affiliative and disaffiliative stances. We propose that an analysis of transformative continuations thus leads us to a consideration of both the degree to which participants may orient to these as (dis)affiliative, as well as the ways in which the respective participants may be held accountable for such instances of joint production.
\end{abstract}

Keywords: joint production, joint utterance, affiliation, alignment, Japanese, interactional pragmatics, transformative continuation

\section{Introduction}

It has long been observed that participants in interaction can contribute to the same semantically coherent syntactic unit (Sacks 1992a). Cases where participants complete or extend the utterances or turns of others have been labelled in various different ways by researchers, including as "joint productions” (Sacks 1992b), “collaborative turn sequences” (Lerner 1987, Lerner 1991, Lerner 2004a), “joint

\footnotetext{
*Corresponding author: Michael Haugh, School of Languages and Linguistics, Griffith University, Nathan, Australia, E-mail: m.haugh@griffith.edu.au Yasuko Obana, School of Science and Technology, Kwansei Gakuin University, Hyogo Prefecture, Japan, E-mail: yobana@kwansei.ac.jp
} 
utterance constructions" (Hayashi 2003), “co-constructed utterances” (e.g., Helasvuo 2004; Rühlemann 2007), “collaborative productions” (e.g., Ferrara 1992; Ono and Thompson 1995; Szczepek Reed 2006), and "cross-person compound contributions" or "split utterances” (e.g., Howes et al. 2011). What unites these different analytical approaches is their common focus on characterizing "a domain of practices by which a speaker produces an utterance that is designed to grammatically continue (and sometimes complete) an ongoing utterance initiated by another speaker" (Hayashi 2003: 1; emphasis added).

A productive line of research in relation to joint productions to date has been the study of practices by which one speaker completes or extends an utterance or turn initiated by another speaker (e.g., Antaki et al. 1996; Hayashi 2003; Kushida 2006; Lerner 1987, Lerner 1991, Lerner 2004a; Szczepek Reed 2006). Such completions or extensions generally progress the action implemented in the prior utterance or turn in some way or another. However, work has shown that grammatically fitted continuations of prior turns or utterances by other speakers do not necessarily forward that prior turn's action. Hayashi (2001, Hayashi 2003), for instance, demonstrates that in the case of "postpositioninitiated utterances" in Japanese, "the second speaker steers or redirects the projected trajectory of another speaker's ongoing utterance by employing a particular grammatical/turn-constructional practice to build a new utterance off of another's prior utterance” (Hayashi 2003: 173; emphasis added).

This kind of redirecting of the projected trajectory of a prior speaker's utterance or turn through a grammatically fitted continuation is not limited to instances of postposition-initiated utterances though. In some cases, joint productions are implemented through continuations that constitute non-serious "wisecracks" (Lerner 1996b), as seen in Excerpt (1).

(1) [GTS] (Lerner 1996b: 311)

1 Dan: Now when the group reconvenes the (.) group reconvenes

2 in two weeks=

3 Roger: =they're gunna issue strait jackets

In other cases, these grammatically fitted continuations are arguably more "devious" or even "hostile" in design, as Gregoromichelaki and Kempson (2013: 198) point out.

(2) (Gregoromichelaki and Kempson 2013: 199)

$1 \mathrm{~A}$ : In fact what this shows is

2 B: that you are an idiot. 
These kinds of joint productions, where the projected trajectory of a prior speaker's utterance or turn is redirected, involve a subsequent speaker "borrow [ing] another's syntactic construction and semantic content in order to insert something independently of his/her own" (Szezepek 2000: 23). As Kempson et al. (2013) argue, then, joint productions do not necessarily involve a recipient guessing what the first speaker might have intended, based on shared experience or knowledge, but may involve "one interlocutor freely join[ing] in on what the other person is saying, adding to it, modifying it, often leading the conversation in directions that might not have been intended by either party" (Kempson et al. 2013: 108). It follows in such instances that questions of accountability, that is, who is - or are - held morally accountable for these kinds of joint productions, and the social actions and stances instantiated through them, comes to the fore. Such cases also raise questions about the interpersonal or relational work that can be accomplished through joint productions. While joint productions may indeed in some cases be a vehicle for showing or building affiliation (Ferrara 1992; Hayashi 2013, Hayashi 2014; Lerner 1996b), namely, a stance that is "supportive of social solidarity" (Heritage 1984: 269), they may also in some cases disguise or mask a disaffiliative stance, namely, one that is "destructive" of social solidarity (Heritage 1984: 269) to varying degrees.

In this paper, building on these observations about grammatically fitted continuations that somehow alter or redirect the projected trajectory of a prior speaker's utterance or turn, and the concomitant (dis)affiliative stances they may implement, we focus on cases in Japanese interaction where grammatically fitted continuations of one speaker's turn or utterance by another speaker effects some kind of transformation of the action or stance implemented by that prior turn. In other words, we consider instances where through grammatically fitted continuations a speaker construes the prior speaker's turn as implementing another action or stance other than that which it appeared designed to occasion, thereby effecting its transformation. We term these kinds of joint production "transformative continuations," as while they overlap with some instances where speakers graft new utterances onto previous ones through postpositions (cf. Hayashi 2001, Hayashi 2003), they are not limited to such cases in Japanese. We also suggest that an analysis of transformative continuations leads us to consider both the degree to which participants may orient to them as (dis)affiliative, as well as the ways in which the respective participants may be held accountable for such instances of joint production.

In the following section, we start by outlining previous research on joint productions. We summarize key distinctions that have been made in relation to 
the syntactic architecture and format of joint productions, as well as the social actions and activities that they have been found to accomplish. We then introduce, in Section 3, our dataset and analytical approach, including the key analytic notions that inform our subsequent characterization of transformative continuations. In Section 4, we move to characterize in more detail transformative continuation as a practice by which joint productions can be accomplished in Japanese interaction, as well as to discuss how affiliative, ostensibly affiliative, and disaffiliative stances can be accomplished by participants through these kinds of transformative continuations. Finally, we briefly outline the implications of our analysis for the study of not only joint productions, but also turn continuation more broadly.

\section{Prior work on joint productions}

\subsection{Joint productions and their syntactic architecture}

One key distinction that has emerged in common across various different disciplinary approaches to joint productions is that between the completion of prior grammatical units-in-progress (i.e., antecedents) and the extension or expansion of those antecedents through various kinds of grammatically fitted continuations (Ono and Thompson 1995). ${ }^{1}$ Completions encompass instances of joint productions where the addition of grammatical units is required in order to make the utterance in question syntactically well formed, as illustrated in Excerpt (3), where Dan's utterance in lines 1 and 3 is completed through Roger's continuation in line 5.

(3) [GTS] (Lerner 1991: 447)

1 Dan: it seemed to be

$2 \quad($.

3 Dan: to Ken at least

4 (.)

5 Roger: the wrong kind.

1 The terms "antecedent” and "continuation" are borrowed from Howes et al. (2011: 287). They refer to talk that precedes and follows, respectively, a change of the speakers who are contributing to the joint production in question. 
Completion-type joint productions have been labelled in various ways, including as "collaborative completions" (Antaki et al. 1996; Bolden 2003; Díaz et al. 1996; Lerner 1991; Local 2005; Poesio and Rieser 2010), "pre-emptive” or “anticipatory completions” (Lerner 1991, Lerner 1996a, Lerner 1996b, Lerner 2004a), “coparticipant completions" (Hayashi 1999, Hayashi 2003; Lerner and Takagi 1999), or “collaborative unison" (Kushida 2006; cf. Lerner 2002). Lerner (2004a) points out that in cases where the completion is addressed to the speaker of the antecedent, "the original speaker thereby maintains authority over the turn's construction even when completed by another" (Lerner 2004a: 225; emphasis added). Such instances have thus been argued to constitute a form of "conditional entry" into the first speaker's turn (Lerner 1996a), where the first speaker remains the final arbitrator on the appropriateness of the recipient's completion (Antaki et al. 1996; Lerner 1989, Lerner 2004a). This can be seen in the way in which the speaker of the antecedent may ratify, reject, or sequentially delete the continuation by the second speaker through "yeah" or "no" responses (Haugh 2010), or “delayed completions" (Lerner 1989), for instance, following the pre-emptive completion.

Extensions, on the other hand, involve instances where talk that is syntactically dependent is latched on to a previously syntactically complete utterance (Howes et al. 2011: 284; cf. Couper-Kuhlen 2011: 504, fn. 11), as we can see in Excerpt (4). Here, Roger and then Al extend Ken's initial utterance.

(4) [GTS] (Sacks 1992a: 300)

1 Ken: We were in an automobile discussion

2 Roger: discussing the psychological motives for

3 (): hhhhhh

$4 \mathrm{Al}$ : drag racing on the street.

As Sacks (1992b: 58) went on to observe in relation to this example, "it's not an incomplete sentence that's continued, it's something that is in its fashion even more interesting - a complete sentence turned into an incomplete sentence." In the case of extension-type joint productions, then, the continuation in question is grammatically fitted to a prior turn that is already possibly syntactically complete, which means the original speaker does not necessarily have the same degree of authority over the extension as he or she appears to have over completions - at least those completions that are directed at him or her as the addressed recipient (Hayashi 2014). Extension-type joint productions have also been studied in various guises, albeit to a lesser extent than completion-type 
joint productions, including as "collaborative extensions" (Szczepek Reed 2006) or "expansion co-constructions" (Rühlemann 2007). ${ }^{2}$

A second related distinction in regard to the syntax of joint productions concerns that between "parasitic" versus "non-parasitic continuations" (Sidnell 2012). Non-parasitic continuations are those that are affixed through word or clitic that "grammatically links a host turn constructional unit [TCU] and a continuation (e.g., and or 'n, but, that, which, in, etc.)," but "nevertheless take the shape of otherwise independent TCUs" (Sidnell 2012: 315). For instance, in Excerpt (5) we can observe an instance of non-parasitic other-continuation by Kathy in lines 52 and 53 in reference to living between home and university dormitories.

(5) [ICE-AUS: S1A-029: 1:48] (Haugh 2010: 363)

51 Mark: you've never quite got a complete se(hh)t he

52 Kathy: and you go ho:me and you're sort of always waiting (.) to

53 [go back] and like (.)

54 Mark: [mm he]

Parasitic continuations, on the other hand, are those that are affixed to the host by a grammatical item (e.g., a preposition), and so are "[syntactically] dependent on the structure of the host-TCU [turn construction unit]" (Sidnell 2012: 315). They therefore also include instances of "post-positioned" additions to prior utterances that are designed with "recognisable non-beginning[s]" (Hayashi 2001: 337). We have already observed an instance of a completion-type joint production that was accomplished through a parasitic continuation in example (3).

Consequently, while the traditional distinction between completion and extension type joint productions corresponds to the degree of (syntactic) completeness of the antecedent, continuations themselves may also be treated as syntactically complete or incomplete by participants. In other words, when examining joint productions, particularly if we are interested in the syntactic relationship that holds between the antecedents and the continuations, we need to take into account the fact that not only antecedents may be either endcomplete or end-incomplete, but that continuations may also be either startcomplete or start-incomplete (Howes et al. 2011).

It follows, then, that an analytical focus on joint productions as semantically and syntactically coherent units, which are recognized as such by participants, can be usefully informed by the growing literature on turn and TCU

2 Some instances of "postposition-initiated utterances" (Hayashi 2001, Hayashi 2003, Hayashi 2004) also fall into this category. 
continuation (Couper-Kuhlen and Ono 2007; Obana and Haugh 2015; Sidnell 2012). Although much of the work to date has been more focused on turn continuation by the same speaker, such work can be extended to other-continuations (Schegloff 1996: 73; Sidnell 2012). For instance, Couper-Kuhlen and Ono (2007) make a distinction between "glue-ons," that is, increments that are "grammatically fitted to the end of the host," and "insertables," namely, increments which "do not properly fit the end of the prior unit but belong, canonically speaking, somewhere within it” (Couper-Kuhlen and Ono 2007: 515). ${ }^{3}$ of particular relevance to the analysis of joint productions is their discussion of instances of "restructuring glue-ons," where an "initially completed syntactic unit is restructured to be part of a larger syntactic unit" (Couper-Kuhlen and Ono 2007: 541; see also Tanaka 2001; Hayashi 2003). Another type of increment that appears potentially relevant to the analysis of joint productions is that of "reverse-directionality increments" (Lerner 2004b), which involve "syntactically tied utterances that implement a responding action addressed to the speaker of the prior turn (i.e., 'reverse' the directionality of address from that of the prior turn)” (Sidnell 2012: 317, citing Lerner 2004b: 161).

Sidnell (2012) himself goes on to make a distinction between incremental other-continuations that are "action-elaborating," that is, "material which is one way or another syntactically and semantically dependent on the prior turn, its 'host', and continues the prior action" (Couper-Kuhlen and Ono 2007: 515; emphasis added), and those which are "action-initiating” (Sidnell 2012: 317318), namely, those which are responding to that prior action. ${ }^{4}$ An analysis of the underlying syntax or format of other-continuation, which may include in some cases instances of joint productions, thus appears inextricably tied to a consideration of the social actions that are accomplished through them, a point to which we now move to consider.

\subsection{Joint productions, social action, and activities}

While joint productions are broadly identified as instances where two (or more) participants contribute to the saying of a single syntactic unit, work in CA and

3 This distinction draws, in turn, on Schegloff's $(1996,2000)$ broader notion of increments, which encompasses "possible completion[s], followed by further talk by the same speaker, built as a continuation of what had just been possibly completed" (Schegloff 2000: 3, cited in Luke et al. 2012: 156).

4 In some cases, continuations may, of course, be oriented to multiple action trajectories as Gregoromichelaki et al. (2011) point out. 
interactional linguistics has nevertheless also focused attention on what social actions and activities are accomplished, that is, what participants are taken to be doing, through joint productions. Much of the focus in research to date has been on occasions where they are involved in "collaborative activities" or "conjoined participation" (Lerner 1993). These range from instances of collaborative or assisted (story) telling or explaining (e.g., Hayashi et al. 2002; Lerner 1992, Lerner 1993; Lerner and Takagi 1999; Richards 1999; Smithson and Díaz 1996), collaborative complaining or reproaching (e.g., Lerner 2002; Mandelbaum 1993), through to collaborative teasing (e.g., Tholander and Aronsson 2002).

Joint productions have been found, for instance, to be involved in displaying, sharing, and proffering understandings or assessments (Bolden 2003; Hayashi and Mori 1998; Szczepek Reed 2006) or displaying empathetic understanding of another's experience (Hayashi 2003, Hayashi 2014; Kushida 2006), thereby achieving affiliation among participants. They have also been found to be involved in building affiliation through pre-emptive answers or responses that head off incipient disagreement (Hayashi 2003, Hayashi 2014; Hayashi and Mori 1998; Lerner 1996a, Lerner 1996b, Lerner 2002; Mori and Nakamura 2008). In other cases, joint productions are designed to elicit information (Ferrara 1992; Szczepek Reed 2006), or to pursue a response through re-implementing a prior question (Hayashi 2001, Hayashi 2003).

Yet while joint productions have been found to display relational connection or affiliation on the part of participants in various kinds of collaborative activities (Hayashi 2013; Rühlemann 2007; Sacks 1992a), they are not by any means limited in scope to these. A number of researchers have also noted in passing how recipients can "place words" in the mouth of the speaker (Hayashi 2013: 187) through grammatically fitted continuations in order to compete with other speakers for the floor (Lerner 2002: 241), to implement disagreements (Szczepek Reed 2006: 198-199), to heckle a storyteller (Lerner 1996a: 244; Monzoni and Drew 2009: 205-206; Szczepek Reed 2006: 197-198), or to make wisecracks (Lerner 1996b: 311; Robinson 2006: 217). Through joint productions, then, participants may evidently implement not only affiliative stances, but also ostensibly affiliative, as well as covertly or even overtly disaffiliative stances.

In the remainder of this paper, building on this prior work, we focus on instances in Japanese where participants transform the trajectory of a prior turn through grammatically fitted continuations. However, before moving to an analysis of instances of what we are here electing to call "transformative continuations," in the following section, we briefly introduce our dataset and analytical framework. 


\section{Data and method}

\subsection{Dataset}

An initial candidate collection of 56 instances of joint productions were identified in a dataset comprising 32 hours of audio-recordings of naturally occurring talk-in-interaction among speakers of Japanese in both the Kanto and the Kansai region (all of which were gained with the informed consent of those participants). ${ }^{5}$ This dataset included 57 recordings of approximately twenty-minute conversations between classmates at Tokyo University of Foreign Studies from the Basic Transcription System (BTS) Corpus of Spoken Japanese, along with ten recordings of approximately twenty-minute conversations between students and faculty and ten recordings of approximately twenty-minute conversations between students at Kwansei Gakuin University, and three one-hour work meetings held at a company in Osaka. This candidate collection was supplemented through a further six examples that were identified in films and television shows. After preliminary analysis of the examples of joint productions in the candidate collection, eleven instances of transformative continuations were then identified for further analysis through close analysis of the recordings, which were transcribed according to standard CA conventions (Jefferson 2004), and to which a morphological gloss has been added (see appendix).

\subsection{Analytical approach}

The candidate examples of joint productions were examined within an interactional pragmatics framework (Arundale 2010; Haugh 2012), an approach to analyzing pragmatic phenomena that is informed by research and methods in ethnomethodological conversation analysis, but also draws from research and methods in linguistic pragmatics more broadly, including corpus analysis. It involves a particular focus on "the study, by observer-analysts, of what particular form-function relationships are taken to mean by user-participants in particular situated, sequential contexts, and how this can vary across those participants" (Culpeper and Haugh 2014: 266). The focus of analysis was therefore not on the interactional mechanics of joint productions in Japanese per se

5 While close study of nonverbal aspects of joint productions is indeed an important area of research (e.g., Hayashi 2005; Iwasaki 2013), our focus was primarily on syntactic and pragmatic aspects of them. 
(cf. Hayashi 2005; Iwasaki 2013), but rather on the interpersonal work accomplished by participants through them.

The distinction made in CA between alignment and affiliation (Steensig 2013; Stivers 2008; Stivers et al. 2011) was nevertheless drawn upon in our analysis as it proved critical to our characterization of transformative continuations. Broadly speaking, alignment concerns the structural level of cooperation, while affiliation concerns the affective level (Stivers et al. 2011: 20), with the latter notion building upon and extending Heritage's (1984) initial characterization of affiliation as a stance that is "supportive of social solidarity" (Heritage 1984: 269). More specifically, aligning responses are ones that support the progressivity of sequentially prior actions (Stivers 2008: 31-32), accept their presuppositions and terms, and match their formal design preference (Stivers et al. 2011: 20), as well as accept the proposed interactional roles (Steensig 2013: 944). ${ }^{6}$ Affiliative responses, on the other hand, are those "actions with which a recipient displays that $s /$ he supports the affective stance expressed by the speaker" (Lindström and Sorjonen 2013: 351) and displays empathy (Stivers 2008), as well as cooperates with the action preference of the sequentially prior action (Stivers et al. 2011: 21; Steensig 2013: 944).

The way in which a particular participation framework, in the sense proposed by Goodwin (1986) and Goodwin (2007), was configured by participants through these joint productions was also considered, with a particular focus on how recipients "can offer competing frameworks for both interpretation and alignment which undercut those of the speaker" (Goodwin 2006: 283; emphasis added). Building on earlier work that has touched upon issues of participant "voice" and accountability with respect to joint productions (Antaki et al. 1996; Duranti 1986; Hayashi 2014: 229; Lerner 1993: 230, Lerner 1996a: 244, Lerner 1996b: 311, Lerner 2002: 238; Szatrowski 2007: 323), we also considered in our analysis how through transformative continuations, prior speakers are construed as accountable for particular actions or stances, and how the "animator" (Goffman 1979) of the continuation may sometimes co-implicate the voice of the animator of the antecedent through the joint production that subsequently emerges.

\section{Transformative continuations}

Transformative continuations encompass instances where grammatically fitted continuations by one speaker of another speaker's prior turn effects some kind

6 For example, an interactional footing as troubles-recipient or advice-giver with respect to troubles telling (Haugh and Chang 2015), or what are also termed "activity roles” (Sarangi 2010). 
of transformation of the action or stance that was implemented by that prior turn. In other words, they involve instances where participants redirect or alter the incipient action trajectory or stance of the prior antecedent through a subsequent continuation that reuses structure provided in the prior speaker's turn.

These grammatically fitted continuations thus arise through what Goodwin and Goodwin (1987) have previously characterized as "format tying," namely, the "reuse of structure provided by earlier talk" (Goodwin 2006: 450; see also Du Bois 2014). We make recourse to the notion of format tying in our analysis as it accommodates the way in which transformative continuations involve "build [ing a] new action by selectively reusing resources provided by a prior action" (Goodwin 2013: 9), as well as also offer "a vivid way of explicitly marking an utterance as a counter to what the speaker's opponent has just said by reusing elements of that prior talk" (Goodwin 2006: 449), particularly in cases where these transformative continuations mask or disguise conflicting stances.

In addition, transformative continuations arise subsequent to turns that can be treated as possibly complete (either syntactically or pragmatically or both), and so invariably involve instances where a possibly complete turn is retroactively treated by the second speaker as incomplete. In other words, they encompass instances where "a first speaker brings an utterance, and the sentence visible within it, to a point of possible completion, and then the next speaker adds a new increment to that sentence (Goodwin 2003: 59, citing Sacks 1992a: 144; cf. Hayashi 2003: 173). It is this retroactive fitting that co-implicates the voice of the producer of the antecedent in the joint production that subsequently emerges, despite this joint production itself evidently being designed (or "authored" - see Goffman 1979) by the animator of the continuation.

Another key feature of transformative continuations is that they are invariably disaligning. What this means is that the continuation in some way resists or rejects the proposed activity, interactional roles, or presuppositions and terms implemented by the prior antecedent turn (Stivers et al. 2011). Yet despite these continuations being disaligning in some form or another, participants may nevertheless implement a range of (ostensibly) (dis)affiliative stances through them.

In the following excerpt from a conversation between two students who are previously unacquainted, for instance, Rie has been asking Tomoko where she lives. There is initially some confusion at the point this excerpt begins about the exact referent for the place Tomoko mentions, namely, Horyuji. This is because it may refer to either the vicinity of Horyuji temple or the vicinity of Horyuji train station, which are in different parts of Nara. 
(6) [SS: TR]

1 Tomoko: wakaru? [Hooryuuji]

understand Horyuji

'(Did you) get it? Horyuji'

2 Rie:

[hai hai]

'yes, yes'

3 Tomoko: Hooryuuji=

'Horyuji'

4 Rie:

$=$ no chikaku desu $k a$ ?

of nearby Polite Q

'(are you living) near (Horyuji Temple)?'

5 Tomoko: EKI.

Station

'(near Horyuji) STATION'

6 Rie: metcha kakkoii desu ne.

very cool polite MD

'very cool, indeed.'

$7 \quad$ (.)

8 Tomoko: tte iwareru yoo ni natta otona ninatte.

Quote say.Pass become Past adult become.TE

'(so I have been) told since (I) became grown-up.'

9 Rie: ha ha ha

'ha ha ha'

Rie initially proffers the vicinity of Horyuji temple (line 4) as glue-on to Tomoko's prior turn (line 3) (Couper-Kuhlen and Ono 2007), thereby turning Tomoko's answer into a question through this grammatically fitted continuation. This candidate answer is subsequently corrected (line 5) by Tomoko, who clarifies that she lives near Horyuji station. It thus constitutes a example of a reverse-directionality increment (Lerner 2004b).

However, the transformative continuation that is of interest here actually follows in lines 6-8. It appears to be occasioned by Rie complimenting Tomoko on where she lives, namely, that it is very "cool” (kakkoii). Notably, this positive assessment is followed by ne in turn-final position, which proposes that it constitutes a shared perspective that requires confirmation from Tomoko (Hayashi 2014: 231). This stance marker is thus also a way for Rie to downgrade her entitlement to be making such an assessment in the first place (Morita 2012: 306), given it is Tomoko rather than Rie who actually lives there. This interactional move is important in this case since first-positioned assessments are often 
associated with claims to "superior access, expertise, authority and rights to assess the matter in question” (Heritage 2002: 200). However, Rie's compliment is nevertheless designed in a way that proffers (dis)agreement with the positive assessment as a relevant next, and agreement as the preferred response.

Yet rather than directly accepting the compliment, Tomoko elects to deflect it (Pomerantz 1978) through a post-positioned quotative that retroactively treats Rie's prior possibly complete utterance as part of a restructured glue-on (CouperKuhlen and Ono 2007). Notably, the action this format tying delivers is disaligning, as it does not accept the underlying terms of Rie's compliment. While Rie's positive assessment was evidently rooted in her own subjective perspective, Tomoko construes the positive assessment as one that is implicitly claimed to be widely shared (given Tomoko has heard it many times). Tomoko thus alters the terms of agreement (Stivers and Hayashi 2010) from being that she agrees with Rie that living nearby Horyuji station is cool, to agreeing that many people have said living near Horyuji station is cool. By reconstruing Rie's compliment as a generalized statement, Tomoko also indirectly indicates appreciation for Rie's compliment by implicitly agreeing with the positive assessment so construed.

Notably, however, by avoiding grounding her agreement in her own subjective perspective, Tomoko also avoids a potentially dispreferred positive assessment of self, while at the same time avoiding a potentially dispreferred disagreement with that positive assessment. In that sense, her transformative continuation, while disaligning with the terms of Rie's compliment, is nevertheless affiliative in that she is attempting to head off an incipient disaffiliative response (Hayashi 2001, Hayashi 2014). This kind of transformative continuation thus appears to constitute a practice for addressing the more general problem of how to deal with the multiple preference structures invoked by positive assessments directed at self, namely, the preference for agreement versus the preference for avoiding self-praise (Pomerantz 1978).

Rie's subsequent laughter in line 9 offers further evidence that she is orienting to the way in which the terms of her prior compliment in line 6 has been reconstrued through this grammatically fitted continuation. By affiliating with it in third position as lighthearted rather than serious (Holt 2014), she is also at the same time mildly resisting Tomoko's reconstrual of her prior compliment. More specifically, Rie appears to be resisting the way in which Tomoko construes her as accountable for alluding to a generally held view, rather than a personally held view that she wishes to share with Tomoko, as well as the way in which her voice has been embedded within Tomoko's subsequent turn.

In the next interaction, a professor, Hosokawa, is chatting with a student, Tanaka. Prior to this excerpt, the two interactants have been talking about how 
Hosokawa looks young for his age. Hosokawa has just suggested it may be something to do with his DNA, thereby implying that others in his family are the same.

(7) $[\mathrm{ST}: \mathrm{TH}]$

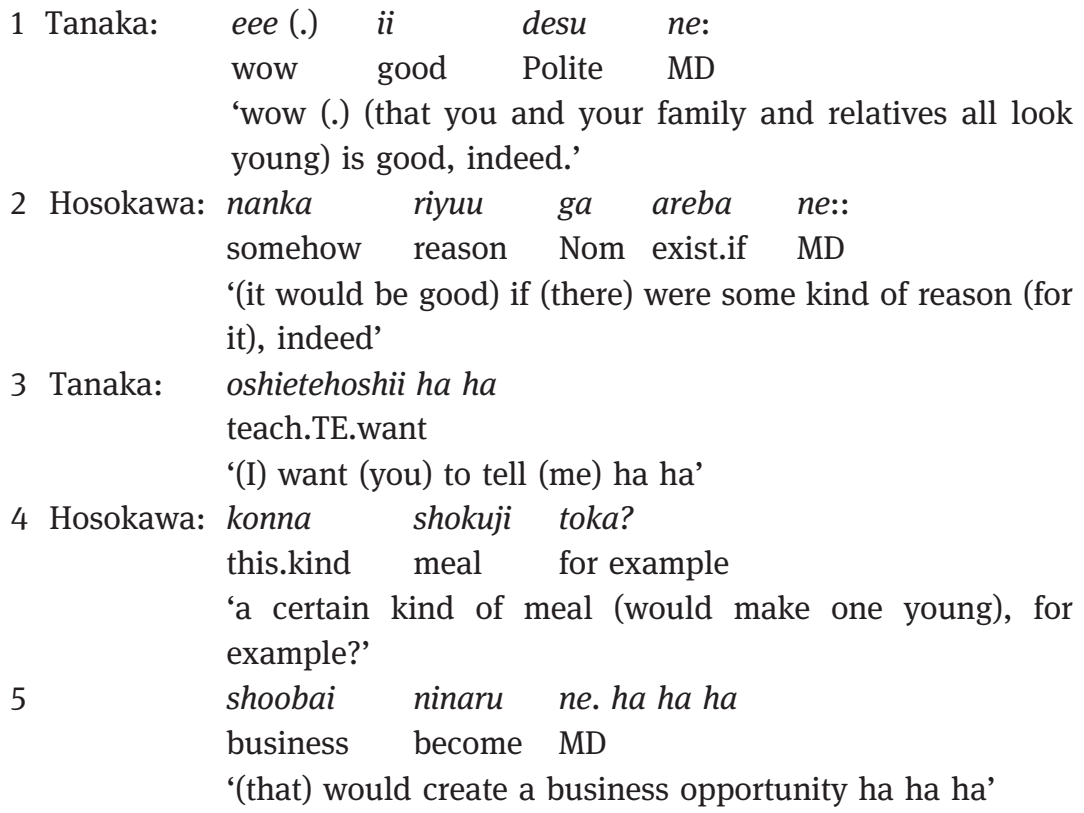

In line 1, Tanaka responds with a positive assessment, which here is used to indicate a kind of friendly envy or admiration as indicated by the stretched ne: a prolonged mood marker. Hosokawa responds in line 2 with what appears to be a deflection of this positive assessment (Pomerantz 1978), as he implies there is no particular reason for the way in which he looks younger than his age, thereby simultaneously avoiding disagreeing with Tanaka's prior assessment, and yet not displaying agreement with it, either.

However, rather than responding with agreement, and thereby accepting Hosokawa's deflection of the positive assessment, Tanaka proffers an insertable (Couper-Kuhlen and Ono 2007) in line 3 that recycles Hosokawa's talk prior to the turn-final ne: in its literal sense in service of a new action, namely, a request that Hosokawa offer Tanaka tips about how to stay looking young (if there are indeed specific ways to do so). In other words, Tanaka construes Hosokawa in the context of this request as suggesting there may be ways to stay looking young by stripping away the implication delivered by Hosokawa's prior turn that there are none and it is just good fortune on his part. It is in that sense that the 
continuation is transformative. The continuation itself is thus disaligning as it does not support the formal design preference of Hosokawa's prior turn for an agreeing (or disagreeing) response.

The request that is realized through this transformative joint utterance is framed, however, as an ostensibly mock or non-serious one, as the turn-final laughter here serves to invite laughter from Hosokawa (Jefferson 1979). Hosokawa continues this non-serious frame in his response in lines 4 and 5, when he proposes the meal he is eating might help, and then wistfully suggests that if this were true he could become rich, followed by laughter, which here serves to mark these suggestions as laughables (Glenn 2003; Holt 2010), that is, as non-serious.

Notably, then, while this continuation by Tanaka recycles Hosokawa's prior deflection of a positive assessment as part of a non-serious request by Tanaka for tips about how to look so young, and so is disaligning, it is designed and treated as affiliative - in Heritage's (1984: 269) sense that it is "supportive of social solidarity" - through a shift from a serious to a non-serious frame. The accomplishment of (dis)affiliation through transformative continuations is thus evidently a locally situated accomplishment of participants.

The final instance of a transformative continuation we consider here is from a conversation between Kitagawa, who is a student, and Fukushima, who is a professor, who are previously not acquainted. Fukushima has been up to this point talking about his interest in travelling on cruise liners. The excerpt begins as Fukushima starts talking about his preparations for such trips, in particular the need to buy special shoes, since ocean liners enforce a strict dress code.

(8) $[\mathrm{ST}: \mathrm{FK}]$

1 Fukushima: kutsu mo kawa na akan toka (.) nanka <kekkoo> shoes too buy must like somehow certainly 'for example, inevitably buying shoes, so certainly' [ha ha ha] 'ha ha ha'

3 Kitagawa: [tanoshii ] ha ha= enjoyable 'that's enjoyable ha ha'

4 Fukushima: =monoiri nan desu. expenditure Cop.Nomi Polite 'expenses, indeed'

5 Kitagawa: naruhodo. '(I) see' 
The excerpt begins in line 1 with Fukushima offering an example of the preparations required for going on cruise liners (in Japan at least), including the need to buy shoes. However, while it appears to be projecting an assessment of that activity, it is Kitagawa who offers an assessment in line 3, while Fukushima himself begins laughing, thereby implicitly treating this need to have to buy special shoes as a laughable (Glenn 2003; Holt 2010). However, while Kitagawa's assessment is grammatically fitted to Fukushima's prior turn as a glue-on (Couper-Kuhlen and Ono 2007), it is disaligning as it does not forward the incipient negative assessment that is projected through "nanka <kekko>" ('somehow certainly'), that is, something like taihen ('difficult') or okane ga kakaru ('costs money'), but rather proffers a positive assessment, tanoshii ('enjoyable'). Given this lack of alignment, and the turn-final laughter on Kitagawa's part that follows, it appears that Kitagawa is proposing a shift to a non-serious or ironic footing here (Clift 1999), and inviting Fukushima to laugh (Jefferson 1979) about the ironic stance he is taking. It is in this sense, then, that it constitutes a proposed transformative continuation, albeit one that is broadly affiliative in the sense proposed by Heritage (1984).

However, this shift to a non-seriousness frame is subsequently resisted by Fukushima (Holt 2013) through a delayed completion in line 4, whereby he “deletes the sequential relevance” (Lerner 1989: 175) of Kitagawa's prior continuation, and instead maintains a serious stance. This reiteration of a serious stance accomplished by Fukushima through this delayed completion is also evident from the lack of laughter in this continuation (line 4), which contrasts with the laughter that accompanied the delivery of the antecedent (lines 1 and 2). In this way, then, the proposed transformative continuation and shift to an ironic footing by Kitagawa is resisted, something which is evidently registered by Kitagawa through naruhodo ('I see') (Nishizaka 2011: 253) in the following turn (line 5). Thus, while the transformative continuation on Kitagawa's part appears designed as affiliative, the subsequent delayed completion proffered by Fukushima is disaffiliative with the ironic stance taken by Kitagawa.

\section{Concluding remarks}

Much of the research on joint productions has focused on how various kinds of grammatically fitted continuations forward the incipient action implemented by a prior speaker's utterance or turn. Building on previous work that has focused on how grammatically fitted continuations may shape or redirect the projected action trajectory of another speaker's prior utterance, in this paper we have focused on instances of transformative continuation, where participants 
construe the incipient action trajectory or stance of the prior antecedent as somehow different to how it was originally designed. We have suggested that while transformative continuations sometimes do arise through post-positioned utterances, they are not limited to these grammatical resources. Instead, they are arguably better characterized as arising through format tying, as by reusing structure provided in the prior speaker's turn, the animators of the continuation are able to blend the voice of that prior speaker as a constituent part of the joint production that emerges, and so co-implicate the prior speaker in the reconstrued action or stance. Unlike many cases of joint productions, then, where the speaker who initiates it remains ultimately accountable for its interactional import, in the case of transformative continuations, while the animator of the continuation is accountable for the action and stance implemented through the transformative joint production itself, this accountability is arguably dispersed due to the way in which the first speaker's voice is co-opted through format tying. We have also suggested that while invariably disaligning, transformative continuations may be accomplished not only as affiliative, but as only ostensibly affiliative, or even covertly disaffiliative responses to prior turns.

Finally, although we have drawn from examples in Japanese to illustrate our claims about transformative continuations, it is not our view that such phenomena are restricted to Japanese. Instead what our analysis illustrates, we believe, echoes ongoing work by Goodwin (2013: 21) on how "individual actions emerge from, and use, a consequential past shaped through chains of prior action, providing current participants with a dense, present environment, a rich now, containing many different kinds of resources that can be selectively decomposed, reused and transformed to build a next action." Our contention is thus that ongoing debates about turn and TCU continuation can be usefully informed by studies such as this.

\section{Appendix}

Transcription conventions (from Jefferson 2004):

[ ] overlapping speech

(.) micropause

: $\quad$ elongation of vowel or consonant sound

- falling or final intonation

$=\quad$ latched utterances

underlining contrastive stress or emphasis

CAPS markedly louder

hhh out-breathing

(hh) intra-word aspiration particle 
ha he laugh particles

<words> talk is markedly slowed or drawn out

( ) blank space in parentheses indicates uncertainty about the transcription

Terms used in morphological gloss:

Cop copula, da and its conjugated forms

MD mood marker

Nom nominative case marker

Nomi nominalizer

Pass passive forms, -reru/-rareru

Past past tense, ta

Polite "polite" forms, masu and desu

Q question marker, $k a$

Quote quotation from, to and its variations such as -tte, -toiu

TE the form which bridges between a verb and an auxiliary

\section{References}

Antaki, Charles, Félix Díaz \& Alan F. Collins. 1996. Keeping your footing: Conversational completion in three-part sequences. Journal of Pragmatics 25(2). 151-171.

Arundale, Robert B. 2010. Constituting face in conversation: Face, facework and interactional achievement. Journal of Pragmatics 42(8). 2078-2105.

Bolden, Galina B. 2003. Multiple modalities in collaborative turn sequences. Gesture 3(2). 187-212.

Clift, Rebecca. 1999. Irony in conversation. Language in Society 28(4). 523-553.

Couper-Kuhlen, Elizabeth. 2011. Pragmatics and prosody: Prosody as social action. In Wolfram Bublitz \& Neal Norrick (eds.), Foundations of pragmatics, 491-510. Berlin \& New York: Mouton de Gruyter.

Couper-Kuhlen, Elizabeth \& Tsuyoshi Ono. 2007. “Incrementing” in conversation: A comparison of practices in English, German and Japanese. Pragmatics 17(4). 513-552.

Culpeper, Jonathan \& Michael Haugh. 2014. Pragmatics and the English language. Basingstoke: Palgrave Macmillan.

Díaz, Félix, Charles Antaki \& Alan F Collins. 1996. Using completion to formulate a statement collectively. Journal of Pragmatics 26(4). 525-542.

Du Bois, John. 2014. Towards a dialogic syntax. Cognitive Linguistics 25(3). 359-410.

Duranti, Alessandro. 1986. The audience as co-author: An introduction. Text 6(3). 239-247.

Ferrara, Kathleen. 1992. The interactive achievement of a sentence: Joint productions in therapeutic discourse. Discourse Processes 15(2). 207-228.

Glenn, Phillip. 2003. Laughter in interaction. Cambridge: Cambridge University Press.

Goffman, Erving. 1979. Footing. Semiotica 25(1). 1-29.

Goodwin, Charles. 1986. Audience diversity, participation and interpretation. Text 6(3). 283-316.

Goodwin, Charles. 2003. The power of Schegloff's work. In Carlo Prevignano \& Paul J. Thibault (eds.), Discussing conversation analysis. The work of Emanuel A. Schegloff, 57-64. Amsterdam \& Philadelphia: John Benjamins. 
Goodwin, Charles. 2006. Retrospective and prospective orientation in the construction of argumentative moves. Text \& Talk 26(4/5). 443-461.

Goodwin, Charles. 2007. Participation, stance and affect in the organisation of activities. Discourse and Society 18(1). 53-73.

Goodwin, Charles. 2013. The co-operative transformative organisation of human action and knowledge. Journal of Pragmatics 46(1). 8-23.

Goodwin, Charles \& Marjorie Harness Goodwin. 1987. Children's arguing. In Susan U. Phillips, Susan Steele \& Christine Tanz (eds.), Language, gender and sex in comparative perspective, 200-248. Cambridge: Cambridge University Press.

Gregoromichelaki, Eleni \& Ruth Kempson. 2013. Grammars as processes for interactive language use: Incrementality and the emergence of joint intentionality. In Alessandro Capone, Franco Lo Piparo \& Marco Carapezza (eds.), Perspectives on linguistic pragmatics, 185-216. New York: Springer.

Gregoromichelaki, Eleni, Ruth Kempson, Gregory J. Mills, Ronnie Cann, Wilfried Meyer-Viol \& Patrick G. Healey. 2011. Incrementality and intention-recognition in utterance processing. Dialogue and Discourse 2(1). 199-233.

Haugh, Michael. 2010. Co-constructing what is said in interaction. In T. Enikö Németh \& Károly Bibok (eds.), The role of data at the semantics-pragmatics interface, 349-380. Berlin \& New York: Mouton de Gruyter.

Haugh, Michael. 2012. Conversational interaction. In Keith Allan \& Kasia M. Jaszczolt (eds.), Cambridge handbook of pragmatics, 251-274. Cambridge: Cambridge University Press.

Haugh, Michael \& Wei-Lin Melody Chang. 2015. Troubles talk, (dis)affiliation and the participation order in Taiwanese-Chinese online discussion boards. In Marta Dynel \& Jan Chovanec (eds.), Participation in public and social media interactions, 99-133. Amsterdam \& Philadelphia: John Benjamins.

Hayashi, Makoto. 1999. Where grammar and interaction meet: A study of co-participant completion in Japanese conversation. Human Studies 22(2/4). 475-499.

Hayashi, Makoto. 2001. Postposition-initiated utterances in Japanese conversation: An interactional account of a grammatical practice. In Margaret Selting \& Elizabeth CouperKuhlen (eds.), Studies in interactional linguistics, 317-343. Amsterdam \& Philadelphia: John Benjamins.

Hayashi, Makoto. 2003. Joint utterance construction in Japanese conversation. Amsterdam \& Philadelphia: John Benjamins.

Hayashi, Makoto. 2004. Discourse within a sentence: An exploration of postpositions in Japanese as an interactional resource. Language in Society 33(3). 343-376.

Hayashi, Makoto. 2005. Joint turn construction through language and the body: Notes on embodiment in coordinated participation in situated activities. Semiotica 156(1/4). 21-53.

Hayashi, Makoto. 2013. Turn allocation and turn sharing. In Jack Sidnell \& Tanya Stivers (eds.), Handbook of conversation analysis, 167-190. Boston: Wiley-Blackwell.

Hayashi, Makoto. 2014. Activity, participation, and joint turn construction. In Kaori Kubata \& Tsuyoshi Ono (eds.), Usage-based approaches to Japanese grammar, 223-258. Amsterdam \& Philadelphia: John Benjamins.

Hayashi, Makoto \& Junko Mori. 1998. Co-construction in Japanese revisited: We do "finish each other's sentences". In Noriko Akatsuka, Hajime Hoji, Shoichi Iwasaki, Sung-Ock Sohn \& Susan Strauss (eds.), Japanese/Korean linguistics, 77-93. Stanford, CA: CSLI. 
Hayashi, Makoto, Junko Mori \& Tomoyo Takagi. 2002. Contingent achievement of co-tellership in a Japanese conversation. In Cecilia E. Ford, Barbara A. Fox \& Sandra A. Thompson (eds.), The language of turn and sequence, 81-122. Oxford: Oxford University Press.

Helasvuo, Marja-Liisa. 2004. Shared syntax: The grammar of co-constructions. Journal of Pragmatics 36(8). 1315-1336.

Heritage, John. 1984. Garfinkel and ethnomethodology. Cambridge: Polity Press.

Heritage, John. 2002. Oh-prefaced responses to assessments. In Cecilia E. Ford \& Sandra A. Thompson (eds.), The language of turn and sequence, 196-224. Oxford: Oxford University Press.

Holt, Elizabeth. 2010. The last laugh: Shared laughter and topic termination. Journal of Pragmatics 42(6). 1513-1525.

Holt, Elizabeth. 2013. "There's many a true word said in jest": Seriousness and nonseriousness in interaction. In Phillip Glenn \& Elizabeth Holt (eds.), Studies of laughter in interaction, 69-89. London: Bloomsbury.

Holt, Elizabeth. 2014. Laughter at last: Laughing in third position. Paper presented at the International Conference of Conversation Analysis (ICCA14), University of California Los Angeles, 25-29 June.

Howes, Christine, Matthew Purver, Patrick G.Healey, Gregory J. Mills \& Eleni Gregoromichelaki. 2011. On incrementality in dialogue: Evidence from compound contributions. Dialogue \& Discourse 2(1). 279-311.

Iwasaki, Shimako. 2013. Emerging units and emergent forms of participation within a unit in Japanese interaction. In Beatrice Szczepek Reed \& Geoffrey Raymond (eds.), Units of talk - units of action, 243-275. Amsterdam \& Philadelphia: John Benjamins.

Jefferson, Gail. 1979. A technique for inviting laughter and its subsequent acceptance-declination. In George Psathas (ed.), Everyday language. Studies in ethnomethodology, 79-95. New York: Irvington.

Jefferson, Gail. 2004. Glossary of transcript symbols with an introduction. In Gene Lerner (ed.), Conversation analysis: Studies from the first generation, 13-23. Amsterdam \& Philadelphia: John Benjamins.

Kempson, Ruth, Eleni Gregoromichelaki \& Stergios Chatzikyriakidis. 2013. Joint utterances in Greek and English: Implications for linguistic modelling. Studies in Greek Linguistics 33. 107-129.

Kushida, Shuya. 2006. Soogookooi Chitsujo to Kaiwa Bunseki [Interaction order and conversation analysis]. Kyoto: Sekai Shisoosha.

Lerner, Gene. 1987. Collaborative turn sequences: Sentence construction and social action. Irvine, CA: University of California unpublished PhD disseration.

Lerner, Gene. 1989. Notes on overlap management in conversation: The case of delayed completion. Western Journal of Speech Communication 53(2). 167-177.

Lerner, Gene. 1991. On the syntax of sentences-in-progress. Language in Society 20(3). 441-458.

Lerner, Gene. 1992. Assisted storytelling: Deploying shared knowledge as a practical matter. Qualitative Sociology 15(3). 247-271.

Lerner, Gene. 1993. Collectivities in action: Establishing the relevance of conjoined participation in conversation. Text 13(2). 213-245.

Lerner, Gene. 1996a. On the "semi-permeable" character of grammatical units in conversation: Conditional entry into the turn space of another speaker. In Elinor Ochs, Emanuel Schegloff \& Sandra Thompson (eds.), Interaction and grammar, 238-276. Cambridge: Cambridge University Press. 
Lerner, Gene. 1996b. Finding "face" in the preference structures of talk-in-interaction. Social Psychology Quarterly 59(4). 303-321.

Lerner, Gene. 2002. Turn sharing: The choral co-production of talk-in-interaction. In Cecilia E. Ford, Barbara A. Fox \& Sandra A. Thompson (eds.), The language of turn and sequence, 225-256. Oxford: Oxford University Press.

Lerner, Gene. 2004a. Collaborative turn sequences. In Gene Lerner (ed.), Conversation analysis: Studies from the first generation, 225-256. Amsterdam \& Philadelphia: John Benjamins.

Lerner, Gene. 2004b. On the place of linguistic resources in the organization of talk-in-interaction: Grammar as action in prompting a speaker to elaborate. Research on Language and Social Interaction 37(2). 154-184.

Lerner, Gene \& Tomoko Takagi. 1999. On the place of linguistic resources in the organization of talk-in-interaction: A co-investigation of English and Japanese grammatical practices. Journal of Pragmatics 31(1). 49-75.

Lindström, Anna \& Marja-Leena Sorjonen. 2013. Affiliation in conversation. In Jack Sidnell \& Tanya Stivers (eds.), Handbook of conversation analysis, 350-369. Malden, MA: Wiley-Blackwell.

Local, John. 2005. On the interactional and phonetic design of collaborative completions. In William J. Hardcastle \& Janet MacKenzie (eds.), A figure of speech. A Festschrift for John Laver, 263-282. Mahwah, NJ: Lawrence Erlbaum.

Luke, Kang-kwong, Sandra A. Thompson \& Tsuyoshi Ono. 2012. Turns and increments: A comparative perspective. Discourse Processes 49(3/4). 155-162.

Mandelbaum, Jenny. 1993. Assigning responsibility in conversational storytelling: The interactional construction of reality. Text 13(2). 247-266.

Monzoni, Chiara \& Paul Drew. 2009. Inter-interactional contexts of story-interventions by non-knowledgeable story recipients in (Italian) multi-person interaction. Journal of Pragmatics 41(2). 197-218.

Mori, Junko \& Kanae Nakamura. 2008. Negotiating agreement and disagreement in Japanese: An analysis of designedly ambiguous utterances. In Junko Mori \& Amy S. Ohta (eds.), Japanese Applied Linguistics, 52-79. London: Continuum.

Morita, Emi. 2012. Deriving the socio-pragmatic meanings of the Japanese interactional particle ne. Journal of Pragmatics 44(3). 298-314.

Nishizaka, Aug. 2011. Response expansion as a practice for raising a concern during regular prenatal checkups. Communication \& Medicine 8(3). 247-259.

Obana, Yasuko \& Michael Haugh. 2015. Co-authorship of joint utterances in Japanese. Dialogue \& Discourse 6(1). 1-25.

Ono, Tsuyoshi \& Sandra A. Thompson. 1995. What can conversation tell us about syntax? In Philip W. Davis (ed.), Alternative linguistics: Descriptive and theoretical modes. Amsterdam \& Philadelphia: John Benjamins.

Poesio, Massimo \& Hannes Rieser. 2010. Completions, coordination, and alignment in dialogue. Dialogue \& Discourse 1(1). 1-89.

Pomerantz, Anita. 1978. Compliment responses: Notes on the cooperation of multiple constraints. In Jim Schenkein (ed.), Studies in the organization of conversational interaction, 79-112. New York: Academic Press.

Richards, Keith. 1999. Working towards common understandings: Collaborative interaction in staffroom stories. Text 19(1). 143-174. 
Robinson, Jeffrey D. 2006. Managing trouble responsibility and relationships during conversational repair. Communication Monographs 73(2). 137-161.

Rühlemann, Christoph. 2007. Conversation in context: $A$ corpus-driven approach. London: Continuum.

Sacks, Harvey. 1992a. Lectures on conversation. Volume I. Malden, MA: Blackwell.

Sacks, Harvey. 1992b. Lectures on conversation. Volume II. Malden, MA: Blackwell.

Sarangi, Srikant. 2010. Reconfiguring self/identity/status/role: The case of professional role performance in healthcare encounters. Journal of Applied Linguistics and Professional Practice 7(1). 75-95.

Schegloff, Emanuel. 1996. Turn organization: One intersection of grammar and interaction. In Elinor Ochs, Emanuel Schegloff \& Sandra A. Thompson (eds.), Interaction and grammar, 52-133. Cambridge: Cambridge University Press.

Schegloff, Emanuel. 2000. On turns' possible completion, more or less: Increments and trail-offs. Paper presented at the 1st Euroconference on Interactional Linguistics, Spa, Belgium.

Sidnell, Jack. 2012. Turn-continuation by self and other. Discourse Processes 49(3/4). 314-337.

Smithson, Janet \& Félix Díaz. 1996. Arguing for a collective voice: Collaborative strategies in problem-oriented conversation. Text 16(2). 251-268.

Steensig, Jakob. 2013. Conversation analysis and affiliation and alignment. In Carole A. Chapelle (ed.), The encyclopedia of applied linguistics, 944-948. Malden, MA: Blackwell.

Stivers, Tanya. 2008. Stance, alignment, and affiliation during storytelling: When nodding is a token of affiliation. Research on Language and Social Interaction 41(1). 31-57.

Stivers, Tanya \& Makoto Hayashi. 2010. Transformative answers: One way to resist a question's constraints. Language in Society 39(1). 1-25.

Stivers, Tanya, Lorenza Mondada \& Jakob Steensig. 2011. Knowledge, morality and affiliation in social interaction. In Tanya Stivers, Lorenza Mondada \& Jakob Steensig (eds.), The morality of knowledge in interaction, 3-24. Cambridge: Cambridge University Press.

Szatrowski, Polly. 2007. Subjectivity, perspective and footing in Japanese co-constructions. In Nancy Hedburg \& Ron Zacharski (eds.), The grammar-pragmatics interface. Essays in honour of Jeanette K. Gundel, 313-339. Amsterdam \& Philadelphia: John Benjamins.

Szczepek, Beatrice. 2000. Functional aspects of collaborative productions in English conversation. InLiSt (Interaction and Linguistic Structures) 21. http://www.inlist.uni-bayreuth.de/ issues/21/inlist21.pdf (last accessed 3 September 2015).

Szczepek Reed, Beatrice. 2006. Prosodic orientation in English conversation. Basingstoke: Palgrave Macmillan.

Tanaka, Hiroko. 2001. The implementation of possible cognitive shifts in Japanese conversation. Complementizers as pivotal devices. In Margaret Selting \& Elizabeth Couper-Kuhlen (eds.), Studies in interactional linguistics, 81-109. Amsterdam \& Philadelphia: John Benjamins.

Tholander, Michael \& Karin Aronsson. 2002. Teasing as serious business: Collaborative staging and response work. Text 22(4). 559-595. 


\section{Bionotes}

\section{Michael Haugh}

Michael Haugh is Associate Professor in Linguistics and International English in the School of Languages and Linguistics at Griffith University, Brisbane, Australia. His areas of research interest include pragmatics, intercultural communication, and conversation analysis. He is the author of a number of papers and books, including Im/Politeness, Implicatures (2015, Mouton de Gruyter), Pragmatics and the English Language (2014, Palgrave Macmillan, with Jonathan Culpeper), and Understanding Politeness (2013, Cambridge University Press, with Dániel Kádár).

\section{Yasuko Obana}

Yasuko Obana is Professor in Linguistics at Kwansei Gakuin University, Japan, teaching English to undergraduate students and linguistics to postgraduate students. Her research interests are in pragmatics, particularly politeness and anaphora. She is the author of a number of papers and books, including Understanding Japanese (2000, Kurosio). 